\title{
Hydrocarbon fuels in solid oxide fuel cells: In-situ Raman studies of graphite formation and oxidation
}

\author{
Michael B. Pomfret ${ }^{\mathrm{a}}$, Jonathan Marda ${ }^{\mathrm{b}}$, Gregory S. Jackson ${ }^{\mathrm{c}}$, Bryan W. Eichhorn ${ }^{\mathrm{a}}$, \\ Anthony M. Dean ${ }^{\mathrm{b}}$ and Robert A. Walker ${ }^{\mathrm{a} *}$ \\ ${ }^{\mathrm{a} D e p a r t m e n t ~ o f ~ C h e m i s t r y ~ a n d ~ B i o c h e m i s t r y, ~ U n i v e r s i t y ~ o f ~ M a r y l a n d, ~ C o l l e g e ~ P a r k, ~}$ \\ College Park, MD 20742. \\ ${ }^{\mathrm{b}}$ Department of Chemical Engineering, Colorado School of Mines, Golden, CO 80401 \\ ${ }^{\mathrm{c}}$ Department of Mechanical Engineering, University of Maryland, College Park, College \\ Park, MD 20742.
}

Supporting Information 

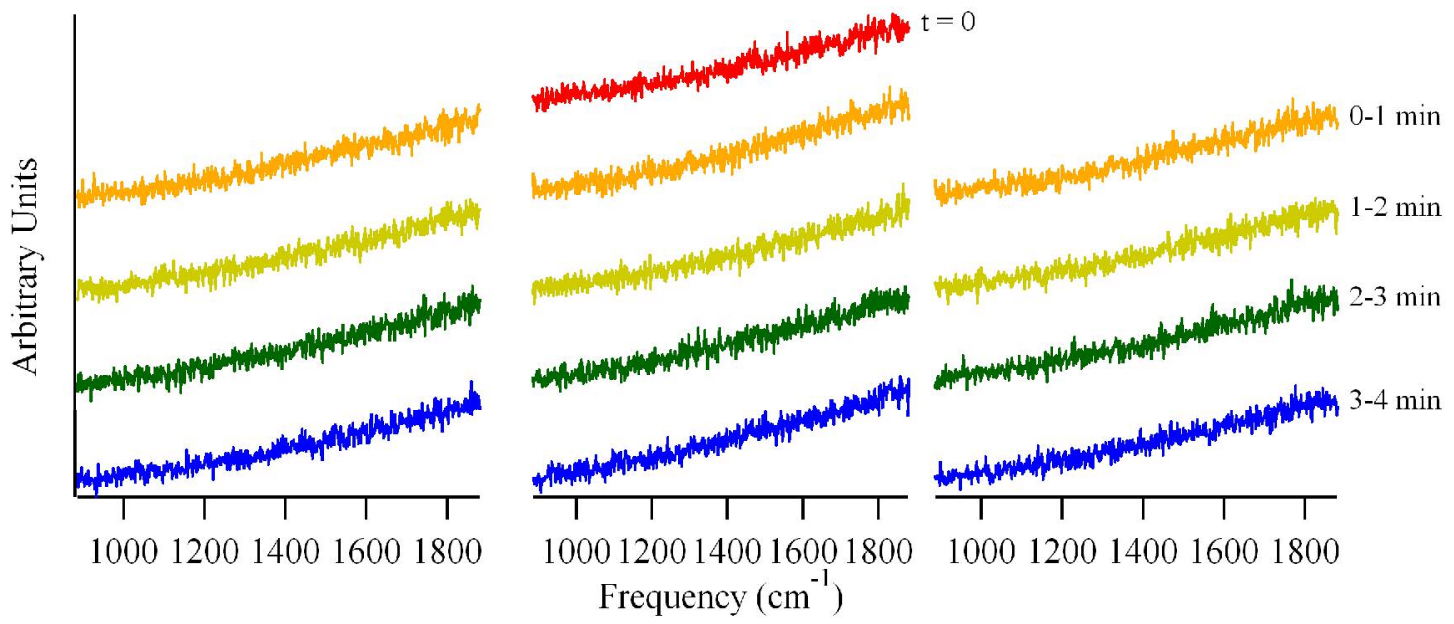

Figure S1. Raman spectra acquired from a Ni/YSZ porous anode operating at $-1.05 \mathrm{~V}$

(OCV) (left), $-0.75 \mathrm{~V}$ (center), and $-0.45 \mathrm{~V}$ (right). The top, featureless trace results from a clean, reduced $\mathrm{Ni} / \mathrm{YSZ}$ anode. A burst of $5 \mathrm{cc}$ of methane leads to no measurable carbon deposition on the anode surface. 


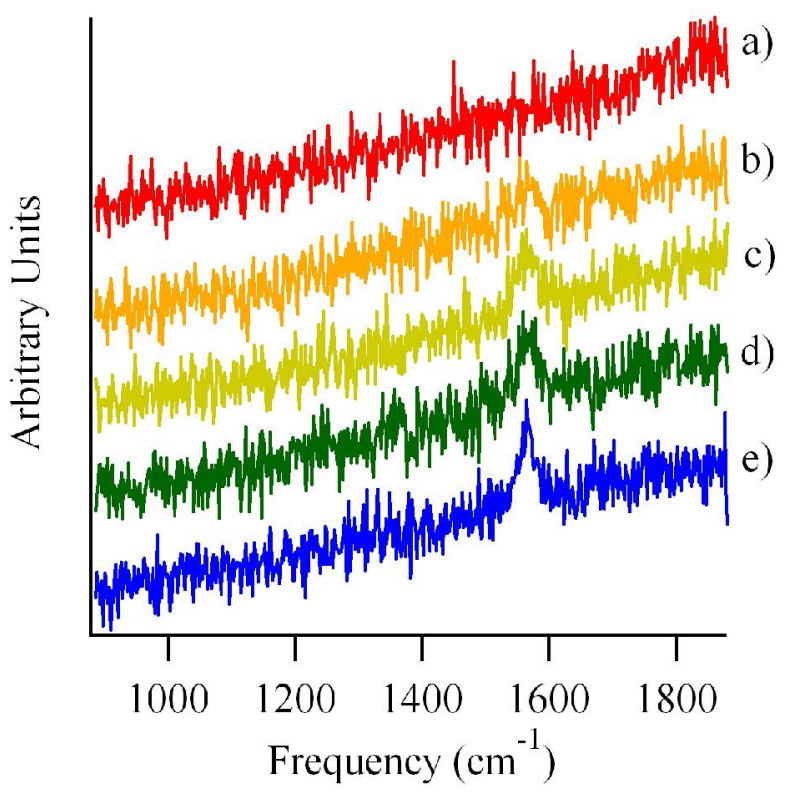

Figure S2. Raman spectra acquired from a Ni/YSZ anode surface as a constant flow of $25 \mathrm{sccm}$ methane is flowed. The top spectrum (a) is of the anode surface before exposure to methane. The subsequent spectra were acquired at 0-1 $\min (\mathrm{b}), 1-2 \mathrm{~min}(\mathrm{c}), 4-5 \mathrm{~min}$ (d), and 8-9 min (e). This series shows a clear, controlled growth of ordered graphite deposits. 


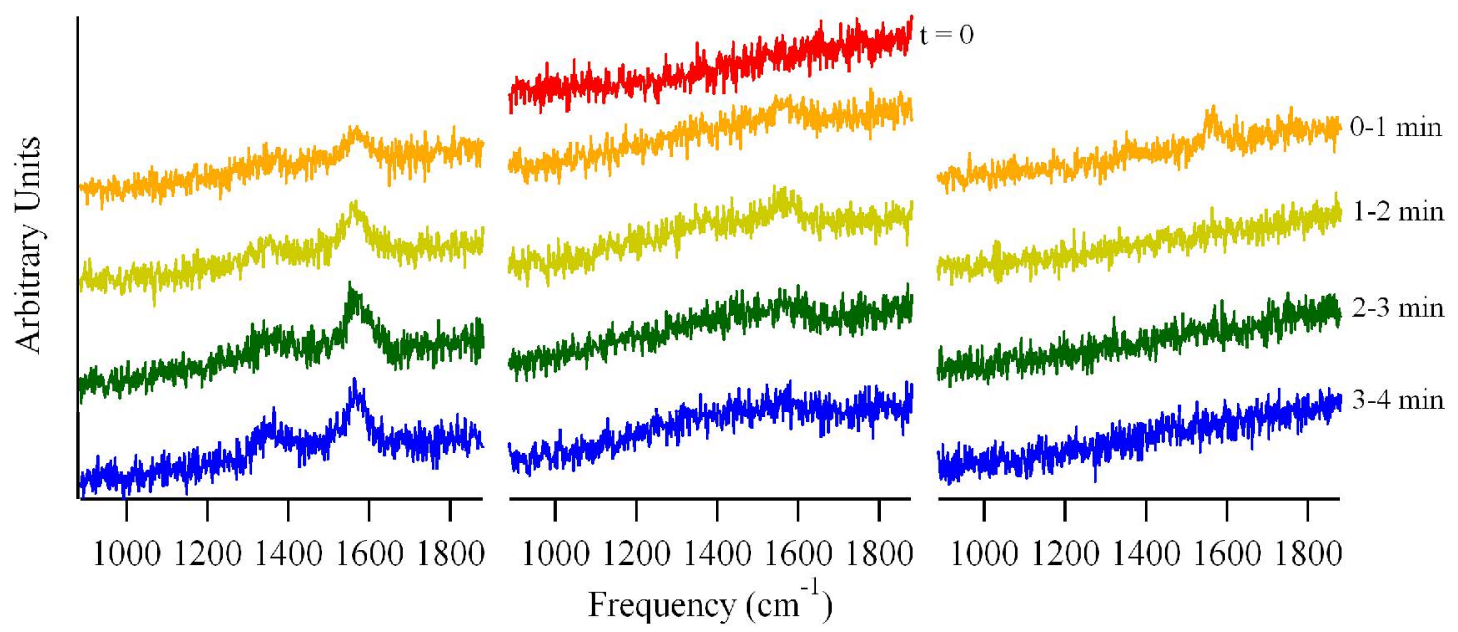

Figure S3. Raman spectra acquired from a Ni/YSZ porous anode operating at $-1.10 \mathrm{~V}$ (OCV) (left), $-0.80 \mathrm{~V}$ (center), and $-0.50 \mathrm{~V}$ (right). The top, featureless trace of the middle column is representative and results from a clean, reduced Ni/YSZ anode. All other spectra are aquired following a single, $5 \mathrm{cc}$ burst of propylene. Following operation at a given overpotential, the anode is re-oxidized, re-reduced and then re-characterized using $\mathrm{H}_{2}$ (in Ar, see the Experimental section) before setting a new overpotential and introducing a new $5 \mathrm{cc}$ burst of propylene. 

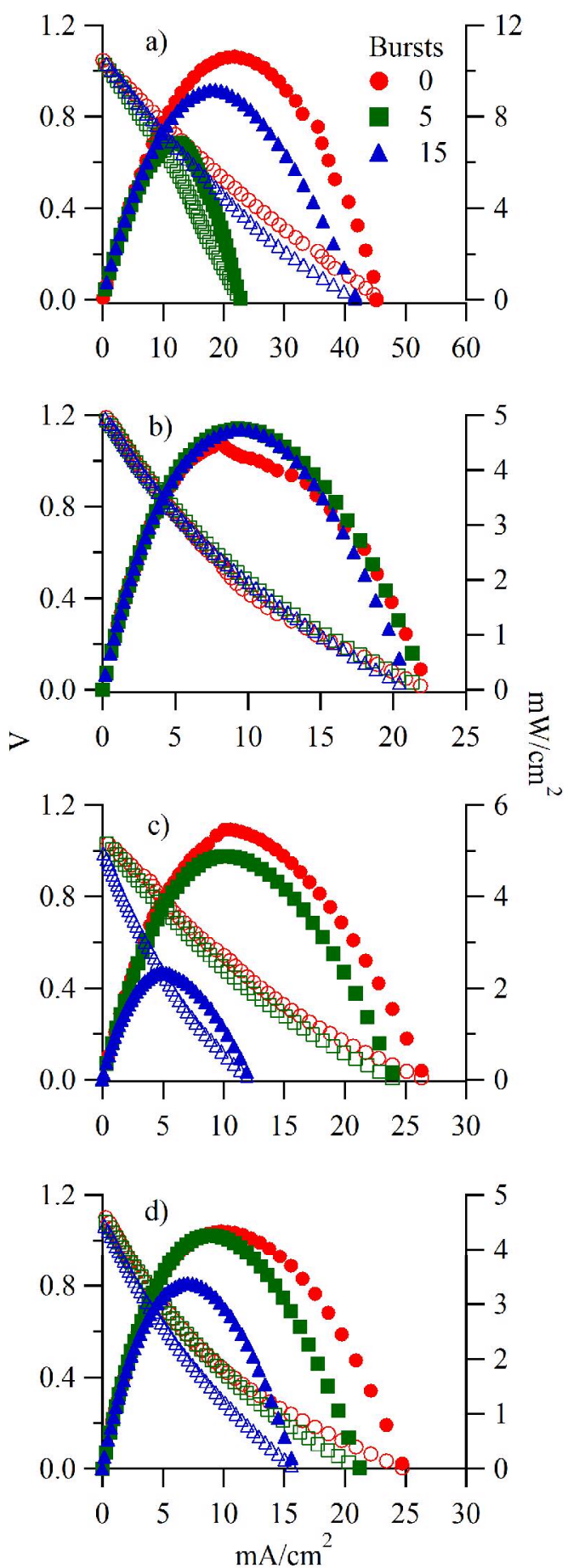

Figure S4. Electrochemical data acquired from cells operated with hydrogen fuel after exposure at $\mathrm{OCV}$ and $715^{\circ} \mathrm{C}$ to $0 \mathrm{cc}$ (circles), $25 \mathrm{cc}$ (squares), and $75 \mathrm{cc}$ (triangles) of a) butane, b) methane, c) ethylene and d) propylene. The graphs shows the voltammetry (open marks) and power density data (closed marks). 